\title{
A METHOD FOR THE QUANTITATIVE DETERMINATION OF PEPSIN BY USING A COLLOIDAL SUSPENSION OF EGG ALBUMIN *
}

\author{
CHARLES HUGH NEILSON, Ph.D., M.D., AND EDMOND BONNOT, M.D. \\ ST. LOUIS, MO.
}

\section{INTRODUCTORY NOTE}

The experimental work in this paper was done during October, November and December, 1909, and January, 1910. A report of the work was made before the St. Louis Medical Science Club in February, 1910. The work was repeated during the year 1911 and read before the St. Louis Society of Internal Medicine in May, 1911. About this time our attention was called to the work of Hata, which was unknown to us. This work is practically identical with our method except in some points of technic. Hata's paper was published in November, 1909. After reading this paper we decided not to publish our results. As Hata's work has received practically no attention, it seemed important to us that this work should be known. It is a valuable method for the quantitative determination of pepsin. We submit this paper as a confirmation of Hata's work. We think our method of procedure easier and better adapted for clinical work than Hata's.

Many methods have been worked out for the quantitative determination of pepsin. Among these, Hammerschlag's method may be mentioned. It is open to the objection that the method of estimating the amount of undigested albumin is determined by Esbach's method, which is inaccurate. Mett's ingenious method has not proved accurate. This method takes ten to twelve hours to complete the determination. Nierenstein and Schiff's modification of Mett's method takes twenty-four hours for its completion. According to Sahli, Volhard's method is better than Mett's method for showing digestion in gastric contents containing but little pepsin. This method is too complicated for ordinary use.

Grützener's carmin method is simple but requires the use of a colorimeter. It also has the objection that its solutions are not stable. The Jacoby and Solms ricin method is valuable, but unfortunately requires an impure form of ricin which is not easily obtained. Their ricin solution gradually deteriorates so that gastric contents tested with old solutions show too high a pepsin content. Fuld and Levison's method requires a

* Manuscript submitted for publication in The ARchives Feb. 6, 1913.

*From the Department of Medicine, St. Louis University School of Medicine. 
vegetable protein, edestin, which is difficult to prepare or obtain. This solution also deteriorates on standing. The Gross method is simple in its technic and the material, casein, is easily obtained.

Schorer's refractometric method seems valuable but it is not adapted for general use. Illoway's method is simple but takes too long to complete the determination. Several other methods such as Meunier's, Bettman and Schroder's, Spriggs' and Lieberman's have been reported but have not been extensively used.

In studying these different methods to determine which was most applicable to a problem we had in hand, we decided on the Jacoby-Solms method. We were unable to obtain the impure ricin used by them without importing. While waiting for this we studied their method carefully. It occurred to us that the probable explanation of the Jacoby-Solms method was due to a protein in the impure ricin which was made colloidal by their procedure, because their solution becomes opalescent when ready for use. On investigating the Fuld and Levison method, or edestin method, we found their solution to be opalescent and therefore, in all probability, edestin is a colloidal condition. With these facts in mind it occurred to us that the colloidal egg albumin solution of Hardy might be used for a quantitative determination of pepsin by the dilution or limit method.

Hardy has shown that egg albumin diluted with distilled water in the proportion of one part egg albumin to nine parts of water, filtered and heated, becomes opalescent. By dialysis and the use of the electric current on this solution in faintly acid or alkaline reaction, he has proved its colloidal nature. This colloidal egg albumin solution is used by us in our method of determining the quantity of pepsin in gastric contents.

\section{METHOD OF MAKING THE COLLOIDAL ALBUMYN SOLUTION}

Our method of making this solution is similar to Hardy's. The white of egg is separated from the yolk and is thoroughly beaten, or, better, vigorously shaken in a flask. It is allowed to stand after shaking until the air bubbles disappear. A measured quantity is diluted nine times with water and filtered through ordinary qualitative filter paper. It comes through the filter paper clear and trans. parent. The solution is acidified slightly by adding two or three drops of an 0.8 per cent. solution of hydrochloric acid to 100 c.c. of the albumin solution. With the albumin of some eggs it is unnecessary to acidify as the albumin becomes opalescent on heating. In other eggs the albumin solution remains clear when heated. This is especially so if the eggs are old. In our method of making the albumin solution we always acidify, as the results are then constant. Hardy does not acidify and, as a result, the solution does not always become opalescent on heating. Hardy's instructions as to the manner of heating are rather indefinite, so that a certain number of failures result even if the albumin solution is acidified. The heating should be done slowly and the temperature should not be raised higher than 60 or $65 \mathrm{C}$. If the solution is heated too rapidly the albumin solution remains clear and transparent. By heating slowly the solution can be made in 
large quantities instead of using small test-tubes as Hardy suggests. We heat the solution in a large test-tube of 100 c.c. capacity or in an Erlenmeyer flask over a naked flame. Made in this way, we invariably obtain an opalescent solution which has all the colloidal properties of Hardy's solution.

\section{METHOD OF MAKING THE COLLOIDAL ALBUMIN SOLUTION READY FOR DIGESTION EXPERIMENTS}

To every 100 e.e. of albumin solution 50 c.e. of an 0.8 per cent. hydrochloric acid are addeã. When a few cubic centimeters of this acid are first added a precipitate may form which will clear as the remainder of the acid is added. The resulting solution is a clear opalescent solution, but somewhat lighter in color than the original, as it has been diluted one-third with the acid. We may, for convenience, call this a stock solution of albumin.

\section{METHOD OF ESTIMATING THE PEPSIN}

All the gastric contents are those of students. The gastric contents were removed at 8 a. m., one hour after a Boas-Ewald test breakfast had been given. The gastric contents were filtered and the pepsin tests made at once. The next step is to make four preliminary dilutions of the filtered gastric content.

Tube 1,2 c.c. gastric content, 23 c.c. distilled water make a dilution 1 to 12.5 . Tube 2,2 c.e. of tube 1 . 2 c.e. distilled water make a dilution 1 to 25

Tube 3, 2 c.e. of tube 1.4 c.c. distilled water make a dilution 1 to 37.5 Tube 4,2 c.c. of tube 1 . 6 c.e. distilled water make a dilution 1 to 50

Into four small test tubes 3 c.c. of the stock colloidal albumin are placed. Into each of these tubes, 1 c.c. of the preliminary dilution is placed, commencing with the weakest solution first in order to avoid the more rapid action of the stronger solutions as these others are added. The time error is so small by this method that it is ignored, as it only takes a few seconds to mix the solutions in the four tubes. The tubes were shaken to insure thorough mixing, placed in a water-bath registering 38.5 to $40 \mathrm{C}$. and the time of placing them in the water-bath is noted. If the method of diluting is placed in table form it may appear clearer.

PRELIMINARY DILUTIONS OF GASTRIC JUICE

1. Dilution 1 to 12.5

2. Dilution 1 to 25 .

3. Dilution 1 to 37.5

4. Dilution 1 to 50 .

FINAL DILUTIONS IN THE COLIOTDAL, ALBUMIN SOLUTION

3 c.c. of acidified albumin solution 1 c.c. tube 1 makes a dilution 1 to 50

3 c.c. of acidified albumin solution 1 c.c. tube 2 makes a dilution 1 to 100

3 c.c. of acidified albumin solution 1 c.c. tube 3 makes a dilution 1 to 150

3 c.c. of acidified albumin solution 1 c.c. tube 4 makes a dilution $I$ to 200

By consulting the accompanying table it is seen that the resulting solutions in the digesting tubes must be 1 to 50 , etc. For instance, 1 c.c. of Tube 1, dilution 1 to 12.5, diluted with 3 c.c. of stock albumin solution must be 1 to 50 , etc. Furthermore, by this method of procedure the percentage of acid in the digesting tubes is 0.2 per cent. For instance, 1 c.c. of 0.8 per cent. $\mathrm{HCl}$ in 3 c.c. of solution makes a 0.2 per cent. solution of hydrochloric acid. The amount of acid in the 1 c.c. of each dilution of the gastric content is ignored, as we have found such small quantities without appreciable influence on the time of digestion. 


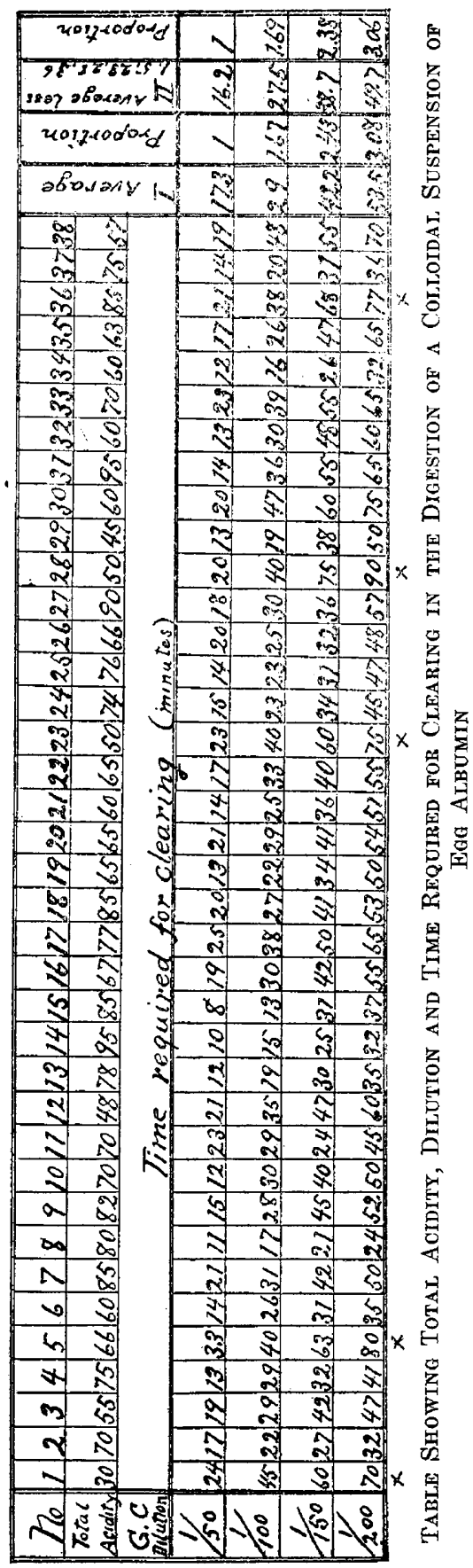


After the tubes have been placed in the water bath, the tube with dilution 1 to 50 is removed at short intervals and examined to determine whether digestion is complete in that tube. Each tube is taken in the order of its dilution and the time of its digestion noted. The end-point of the digestion is when the opalescence has disappeared and the solutions are practically clear. There is always a faint, cloudy appearance after the opalescence disappears. At first this end-point may seem uncertain; but after a few trials one determines this easily. In examining the tubes they must not be placed in direct sunlight or strong light. We read all our tubes at the north window of the laboratory where there is a clear, diffused, reflected light.

The results in this table are consecutive tests made on thirty-eight gastric contents of students. These are considered normal gastric contents as none of them differ much from the so-called normal standard of quantity of gastric contents and total acidity of a Boas-Ewald test breakfast.

It is seen that on the whole, the results are as uniform as we could expect. There is some variation in the time of digestion but not more than in the total acidity. The time of digestion is not proportional to the dilution as the more dilute solutions of the gastric contents digest relatively quicker than the more concentrated.

If we consider the time it takes a dilution of 1 to 50 to digest as one, we find the ratio $1,-1.67,-2.4,-3$ instead of $1,-2,-3,-4$, the ratio by dilution. The column of averages, No. 1 , is made by averaging the time digesting all the 38 gastric contents. Column No. 2 is made by averaging all except $1,5,23,28$ and 36 , which digested so much slower than the others as to be somewhat out of proportion to the others. The ratio here is $1,-1.68,2.4,-2.98$, which is practically the same as that of all the contents.

By this method of procedure, supposedly normal gastric contents in a dilution of 1 to 100 will clear colloidal egg albumin approximately in one-half hour. In gastric analysis we consider a normal total acidity between 40 and 70 . In a determination of pepsin by this method we might consider the pepsin as normal when digestion is finished in a dilution of 1 to 100 in twenty-five to thirty-five minutes. If in this dilution, digestion is completed more rapidly than thirty minutes, we know there is plenty of pepsin. The only question is how far above thirty minutes we may make the limit and still be within so-called normal limits. It seems to us that a digestion in twenty-five to thirty-five minutes should still be considered normal, as the general average for this dilution is twenty-nine minutes.

In another set of experiments on the gastric contents of thirty-four different students, by a different method of diluting, we obtained the following general average: 


\begin{tabular}{|c|c|c|c|}
\hline Dilution & $\begin{array}{l}\text { Average, } \\
\text { Minutes }\end{array}$ & Dilution & $\begin{array}{l}\text { Average, } \\
\text { Minutes }\end{array}$ \\
\hline $1-8$ & $\begin{array}{ll}\ldots \ldots \ldots & 6.0\end{array}$ & $1-122$ & $\ldots \ldots 38.0$ \\
\hline $1-20$ & $\ldots \ldots \ldots$ & $1-140$ & $\ldots \ldots 44.0$ \\
\hline $1-40$ & $\ldots \quad 14.0$ & $1-160$. & 50.5 \\
\hline $1-80$ & . 23.5 & $1-200$ & $\mathbf{5 7 . 0}$ \\
\hline $1-100$ & $\ldots \ldots \ldots 30.0$ & & \\
\hline
\end{tabular}

We see here the general averages approach those of the other set of experiments.

Instead of using the time of digesting as a standard we might establish an arbitrary standard. If we consider the digesting power of a dilution of 1 to 100 in thirty minutes as 100, we would have a standard for comparison. If a pure gastric content digested the solution in a dilution of 1 to 100 in forty minutes, the pepsin power would be less as the time of digestion was longer. In units this would be $6 \%$, as the digestion was 33 per cent. slower. Or if the digestion in the dilution was completed in twenty minutes, the pepsin units would be 133 , etc. The normal limits would vary between $85-116$; we take the limit as varying between twenty-five and thirty-five minutes.

In the routine examination of gastric contents for the quantitative determination of pepsin, all that is necessary at first would be the making a dilution of 1 to 100 and note the time of the digestion. If this took place between twenty-five and thirty-five minutes we could consider the digestion normal. If it took much longer or did not clear up at all, stronger solution should be used. Let us say a dilution of 1 to 10,1 to 25 . If these cleared in twenty-five to thirty-five minutes the digestion power in units would be $1 / 10,1 / 25$ of 100 . Any other dilution that the worker might desire to use could easily be made. Dilutions might be made as follows :

3 c.c. acidified albumin 1 c.c. filtered gastric content makes dilution 1-4

3 c.c. acidified albumin 1 c.c. of 1 to 25 dilution makes dilution 1-10

3 c.c. acidified albumin 1 c.c. of 1 to 6.25 dilution makes dilution $1-25$

In making up small quantities of the albumin solution for use at different times, it occurred to us that the albumin of different eggs might vary in concentration and thus the time of digestion might also vary, when the solution of different eggs was used. We tried a 2 per cent. solution of pepsin on different eggs and found no marked variations. We also tried a gastric content in different dilutions on two dozen different eggs and found the results practically constant.

There is another question which is of importance; that is, whether the acidified albumin solution is stable. These solutions will keep about ten days or two weeks, but at the end of that time the albumin begins to precipitate and, as a result, the time of digestion is shortened. We also found that the end-point in the old solutions is not so sharp as in the tresh solutions. 
The acidified albumin solution with chloroform added in the proportion of one part chloroform to 1,000 albumin solution, keeps from two to three weeks. At the end of three weeks there may be no precipitate of albumin, yet the end-point is not sharp and the resulting time of digestion is somewhat inaccurate.

The time of digestion is not proportional to the quantity of pepsin as measured by the dilution. As the solution of gastric contents becomes more dilute the time of digestion gradually lessens. This suggests the possibility that in the dilution methods such as we have used, we do not obtain the same result we would obtain if the digestion were carried on in undiluted gastric contents. By diluting we may lessen certain inhibitory factors which operate in concentrated gastric contents but not in dilute solutions. However, the results obtained by this method approximate closely the digestive power of a given gastric content. Any marked pathological change in the digestive power of a given gastric content will surely be found by this method, as we have shown conclusively in pathologic cases.

The concentration of hydrochloric acid for the most rapid digestion with this albumin solution is 0.1 per cent. The time of digestion is proportional to the concentration of the albumin used.

The points in favor of this method are:

1. We have a material which is easily obtained.

2. The colloidal albumin solution is easily made.

3. The technic is as simple as any dilution method can be.

4. The time of making a complete determination is under one hour.

5. The results are constant.

Objections to this method:

1. The solution cannot be kept and used indefinitely, as it decomposes.

2. It has the objection that dilution methods do not give the actual digestion as found in concentrated gastric contents.

3. The end-point may seem indefinite to those who use this method for the first time; but experience soon enables one to read and obtain constant results.

\section{REFERENCES}

1. Hata: Ueber die Bestimmung des Pepsin durch Aufhellung von trüben Eiweisslösungen, Biochem. Ztschr., 1909, xxiii, 179.

2. Hammerschlag: Internat. klin. Rundschau, 1895, viii, No. 39.

3. Mett, cited by Pawlow: Die Arbeit der Verdauungsdrüsen, 1898, p. 26.

4. Nierenstein and Schiff: Arch. f. Verdauungskr., 1902, viii, Part 6, p. 559.

5. Sahli: Diagnostic Methods, 1911, p. 468.

6. Volhard: München. med. Wchnschr., 1903, No. 49, p. 2129.

7. Grützner, Pflïgers Arch. f. d. ges. Physiol., 1874, viii, 502.

8. Jacoby and Solms: Ztschr. f. klin. Med., 1907, lxiv, 159.

9. Fuld and Levison: Biochem. Ztschr., 1907, vi, 473. 
10. Gross: Berl. klin. Wchnschr., 1908, xlv, 645.

11. Schörer: Inaugural Dissertation, Berne, 1908.

12. Illoway: Am. Jour. Med. Sc., 1904, cxxxviii, 234.

13. Meunier: Compt. rend., 1901.

14. Bettman and Schröder: Med. Rec., New York, 1903, lxiv, 685.

15. Spriggs: Zeitschr. f. physiol. Chemie, 1902, xxxv, 465.

16. Liebman: München. med. Wchnschr., 1907, p. 1550.

17. Hardy: Jour. Physiol., 1899, xxiv, 288. 